\title{
Aspectos Ecológicos da Determinação Sexual em Tartarugas
}

\author{
Paulo Dias FERREIRA JÚNIOR ${ }^{1}$
}

\section{RESUMO}

Os aspectos ecológicos relacionados à reprodução das tartarugas e de outros répteis que apresentam determinação sexual dependente da temperatura de incubação desempenham um papel crucial no equilíbrio das populaçóes. Nestas espécies a razão sexual dos filhotes é controlada pela temperatura a que os ovos são submetidos durante a incubação. Entender como as características do local da desova afetam a temperatura da incubação é essencial para que se possa argüir sobre os fatores que controlam a ecologia, a reprodução e a distribuição geográfica das tartarugas. Este trabalho de revisão aborda o modo de reprodução das tartarugas e a maneira como a reprodução é afetada pelo meio físico.

PALAVRAS-CHAVE: quelônio, reprodução, nidificação, incubação, sedimento

\section{Ecological aspects of turtle sex determination}

\section{ABSTRACT}

The ecological aspects related to the reproduction of turtles and other reptiles, which present incubation temperature-dependent sex determination, play a crucial role in their population equilibrium. For such species, the sex ratio of hatchlings is controlled by the nest temperature during incubation. To understand how the nest site characteristics affect temperature is essential for considering the factors which control the ecology, reproduction and distribution of turtles. In this paper, we have made a review on the way turtles reproduce and how the physical environment affects reproduction.

KEY WORDS: chelonian, nesting place, incubation duration, sediment

${ }_{1}^{1}$ Mestrado em Ecologia de Ecossistemas. Centro Universitário Vila Velha, Rua Comissário José Dantas de Melo, 21, Bairro Boa Vista, Vila Velha - ES (CEP: 29.102-770).Telefone: (27) 3421-2082, e-mail: pdfj@hotmail.com 


\section{INTRODUÇÃO}

Sob a denominação popular de tartaruga abrigam-se, atualmente, mais de 250 espécies divididas em 14 famílias da Ordem Testudinata (Pritchard \& Trebbau, 1984; Ernst \& Barbour, 1989; Iverson, 1992; Ewert et al., 2004). As tartarugas ocupam os mais diversos ambientes como rios, lagos, pântanos, mares, desertos e florestas, existindo espécies adaptadas a viverem exclusivamente em terra e outras nas águas dos rios, lagos e mares. Estudos originados na década de 1960 demonstraram que a vulnerabilidade de vários répteis antecede a eclosão e tem momentos críticos durante a incubação. A descoberta que a determinação sexual do lagarto Agama agama é controlada pela temperatura de incubação dos ovos abriu um novo campo de pesquisas (Charnier, 1966). Uma determinada faixa de temperatura produz apenas machos e outra, exclusivamente fêmeas, existindo ainda um intervalo de transição onde são gerados ambos os sexos. Esta descoberta descortinou um novo e fascinante cenário de pesquisas que busca determinar os elementos físicos que afetam e influenciam o sexo dos embriōes. Hoje, é consenso que a temperatura é o elemento principal da determinação sexual de inúmeras espécies de tartarugas. A análise dos parâmetros que controlam a temperatura da incubação é uma tarefa árdua, pois no ambiente natural as condiçōes físicas do local da desova e as características meteorológicas variam muito, sendo difícil separar a influência de cada fator, assim como quantificar a sua importância. Os locais de desova diferem entre as espécies ou até mesmo em uma mesma espécie. Os sítios de desova escolhidos pelas tartarugas, por exemplo, distribuem-se por praias e bancos arenosos lacustres, fluviais e marinhos, áreas vegetadas ou campos arenosos abertos, entre folhas e restos vegetais de matas densas e substrato lamoso. Os resultados obtidos nos ninhos naturais apresentam uma maior heterogeneidade, sugerindo que parâmetros diversos daqueles mensurados e monitorados nos experimentos em laboratórios estão interagindo e que, inequivocamente, os ninhos não podem ser considerados como sistemas fechados.

Este trabalho de revisão aborda o modo de reprodução dos quelônios e a maneira como a reprodução é afetada pelo meio físico. Os estudos dos elementos e das condições de contorno envolvidos na determinação sexual dos quelônios mostram um campo aberto a especulaçôes, muitas vezes sem conclusôes que possam ser estendidas ou generalizadas às outras espécies. As relaçōes mais complexas dizem respeito à tentativa de se mostrar uma correlação entre a temperatura de incubação, a duração da incubação e a razão sexual dos filhotes. O foco principal das discussões centra-se nestes três parâmetros, mas freqüentemente outros elementos compõem o cenário das pesquisas, tais como, as características do substrato onde ocorre a incubação, a umidade dos ninhos, o período e a temperatura crítica da determinação sexual e o mecanismo envolvido na diferenciação das gônadas.

\section{PRINCÍPIOS DA DETERMINAÇÃO SEXUAL DEPENDENTE DA TEMPERATURA DE INCUBAÇÃo (DST)}

A descoberta da determinação sexual dependente da temperatura de incubação (DST) chamou a atenção para as condições em que ocorre a incubação. Em inglês são encontradas duas siglas: TSD (temperature-dependent sex determination: Bull, 1980) e EDS (environmental sex determination: Bull et al., 1985) para o termo "determinação sexual dependente da temperatura de incubação". Na DST uma determinada faixa de temperatura induz o desenvolvimento de machos e outra faixa de temperatura, o desenvolvimento de fêmeas. Separando essas faixas termais existe uma zona de transição onde são gerados machos e fêmeas. Neste caso, as condiçōes físicas que regem a incubação terão um papel decisivo na proporção de indivíduos machos e fêmeas produzidos em cada ninho (razão sexual). Para espécies com DST a diferença na razão sexual é devida à influência da temperatura de incubação e não a taxas de mortalidade diferenciadas entre os sexos (Bull \& Vogt, 1979).

Pieau (1971) foi o primeiro a trabalhar com quelônios descobrindo a DST em Testudo graeca e Emys orbicularis. Yntema $(1976,1979)$ mostrou que para Chelydra serpentina há uma relação inversa entre a temperatura e a duração da incubação, e uma diminuiçãao de $2{ }^{\circ} \mathrm{C}$ na temperatura média aumenta em até 20 dias a duração da incubação. Yntema (1979) manipulou a temperatura de incubação ao longo de vários estágios do desenvolvimento embrionário de $C$. serpentina, definindo o período termo-sensitivo, ou seja, o momento em que a temperatura age irreversivelmente sobre a diferenciação das gônadas. $\mathrm{O}$ período termo-sensitivo em tartarugas de água doce (Graptemys, Chrysemys picta e $C$. serpentina) e em tartarugas marinhas (Caretta caretta) é o mesmo e localiza-se no segundo terço do desenvolvimento embrionário (Bull \& Vogt, 1979, 1981; Yntema, 1979; Yntema \& Mrosovsky, 1982; Vogt \& Bull, 1982). Ao tomar como base os estágios do desenvolvimento (Yntema, 1968), e não a duração da incubação, Yntema (1979) criou uma metodologia que permite comparaçôes entre diversas espécies de quelônios, independente da taxa do desenvolvimento embrionário.

A determinação sexual depende do efeito cumulativo da temperatura. No estágio inicial, no primeiro terço da incubação, a temperatura influencia a determinação sexual, mas a reversibilidade é possível. No segundo terço da incubação, a determinação sexual é irreversível (Bull \& Vogt, 1981). Neste estágio, a temperatura atua na síntese de enzimas envolvidas na diferenciação das gônadas (Pieau, 1996). 
A temperatura pivotal, também denominada temperatura crítica ou threshold, define a produção de $50 \%$ de machos e 50\% de fêmeas (Bull, 1980). Quando a embriogênese se processa a temperaturas próximas à pivotal, pequenas diferenças de $1{ }^{\circ} \mathrm{C}$ a $2{ }^{\circ} \mathrm{C}$ são suficientes para alterar a razão sexual dos embrióes (Yntema \& Mrosovsky, 1982). A amplitude da zona de transição da temperatura, em que machos e fêmeas são gerados, é muito variável. Para as tartarugas marinhas Natator depressus e Dermochelys coriacea (Hewavisenthi \& Parmenter, 2000) é de menos de $1^{\circ} \mathrm{C}$, já para Chelonia mydas fica em torno de $4{ }^{\circ} \mathrm{C}$ (Mrosovsky et al., 1984). O efeito das variaçōes da temperatura durante a incubação na razão sexual dos filhotes dependerá da amplitude da zona de transição da temperatura.

Apesar de a temperatura da incubação ser reconhecidamente um fator que afeta a determinação sexual dos embriōes, a taxa de estrógeno é um elemento ainda mais importante, pois embriōes tratados com estrógeno geram fêmeas em temperaturas apropriadas ao desenvolvimento de machos e machos se desenvolvem quando a síntese de estrógeno é bloqueada em uma temperatura que tipicamente produz fêmeas (Wibbels et al., 1994; Pieau, 1996). Mas como é a temperatura de incubação que regula a produção de estrógeno, deduz-se que no ambiente natural a temperatura da incubação é o elemento básico da determinação sexual (Wibbels et al., 1994).

Os estudos sobre DST em quelônios envolvem dificuldades inerentes às características fisiológicas dos animais recémeclodidos. O dimorfismo sexual, na maioria das espécies, somente é visível após alguns anos de vida, sendo que nos embriôes e filhotes recém-eclodidos o meio mais seguro para se aferir o sexo são estudos histológicos. A análise histológica de C. serpentina realizada por Yntema (1976) serve de orientação para outras espécies. Trabalhos recentes mostraram que a partir da aplicação dos princípios da morfometria geométrica foi possível correlacionar o sexo dos filhotes recém-eclodidos das tartarugas de água doce Podocnemis expansa e Chrysemys picta com a forma da carapaça (Valenzuela et al., 2004).

Determinação sexual dependente da temperatura de incubação (DST) e determinação sexual genotípica (DSG)

A DST é o mecanismo mais freqüente entre os quelônios (Figura 1), mas em algumas espécies a determinação sexual independe da temperatura de incubação. A determinação sexual genotípica (DSG) é menos freqüente em quelônios, mas é comum em cobras e lagartos. Em inglês tem-se a sigla GDS (genotypic sex determination: Bull, 1980). Já foram testadas 80 espécies quanto ao modo de reprodução, destas, 64 apresentaram DST (Tabela 1) e 16 apresentaram DSG (Tabela 2). Além das 49 espécies apresentadas na tabela 1 , Ewert et al. (1994, 2004) apontaram 15 espécies com DST sem informar a temperatura pivotal ou o local da coleta dos

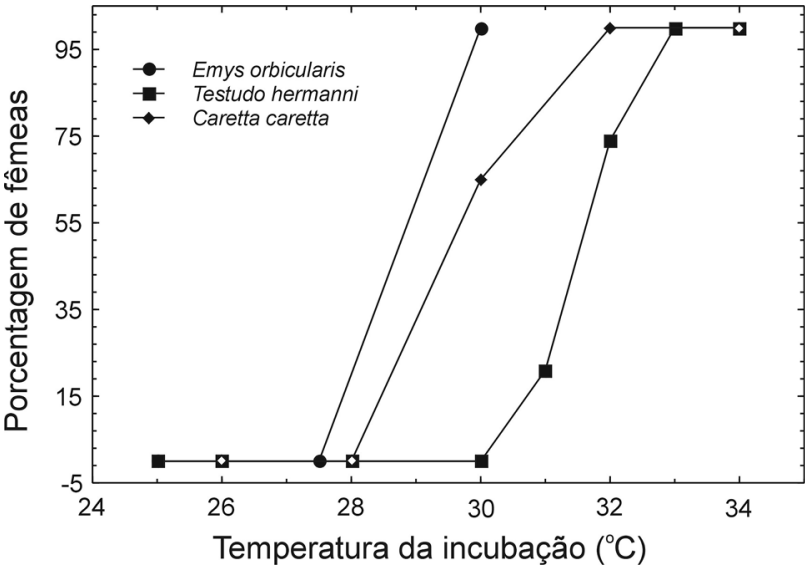

Figura 1 - Relação entre a temperatura da incubação e a razão sexual de quelônios. A razão sexual será expressa pela porcentagem de fêmeas. Baixas temperaturas de incubação induzem a produção de machos e altas temperaturas de incubação levam ao desenvolvimento de fêmeas. A DST é comum em tartarugas marinhas (Caretta caretta), terrestres (Testudo hermanni) e de água doce (Emys orbicularis). Fonte dos dados: C. caretta (Yntema \& Mrosovsky 1979), T. hemanni (Eendebak 1995) e E. orbicularis (Pieau 1971).

ovos. Dessas espécies sete pertencem à família Emydidae (Deirochelys reticulata, Emydoidea blandingii, Pseudemys concina, P. floridana, P. nelsoni, P. texana, Terrapene carolina) e cinco à família Geomydidae (Chinemys nigricans, C. reevesii, Mauremys annamansis, Rhinoclemmys areolata, $R$. pulcherrina). Essa amostragem abarca 12 das 14 famílias de quelônios e cerca de $70 \%$ das espécies conhecidas de tartarugas ainda não foram testadas quanto ao seu modo de reprodução. Cromossomos sexuais são reconhecidos em cobras e lagartos, mas são aparentemente raros em anfisbênias e quelônios e ausentes em crocodilianos e na tuatara (Sphenodon punctatus) (Bull, 1980; Janzen \& Paukists, 1991a).

Uma questão filogenética, aparentemente simples, mas com profundas implicaçôes evolutivas ainda permanece sem um veredicto conclusivo e diz respeito a quem surgiu primeiro, se a DST ou a DSG. Com base em estudos filogenéticos foi sugerido que DSG é o mecanismo ancestral dos vertebrados (Head et al., 1987; Wibbels et al., 1994; Janzen \& Krenz, 2004). Para as tartarugas, a DST seria o mecanismo primitivo (Ewert \& Nelson, 1991; Janzen \& Paukstis, 1991b) e a DSG surgiu de forma independente pelo menos seis vezes dentro desse clado (Janzen \& Krenz, 2004). Para lagartos a DST teria se originado, independentemente, pelo menos três vezes. Dessa forma, alteraçôes no mecanismo da determinação sexual seriam relativamente freqüentes nos vertebrados (Valenzuela $\&$ Lance, 2004).

A seleção natural favorece a DST quando um indivíduo é fortemente influenciado pelas condiçôes ambientais e quando ele tem pequeno controle sobre as condiçôes ambientais 
Tabela 1 - Espécies com determinação sexual dependente da temperatura de incubação (DST) (* espécies brasileiras, ‡ espécies com duas temperaturas pivotais).

\begin{tabular}{|c|c|c|c|c|}
\hline \multirow{2}{*}{$\begin{array}{l}\text { Família } \\
\text { Tartarugas marinha }\end{array}$} & Espécie & Temperatura Pivotal $\left({ }^{\circ} \mathrm{C}\right)$ & \multirow[t]{2}{*}{ Local } & \multirow[t]{2}{*}{ Autor } \\
\hline & & & & \\
\hline \multirow[t]{20}{*}{ Cheloniidae } & Caretta caretta* & 29,7 & África do Sul & Maxwell et al. (1988) \\
\hline & & 28,6 & Austrália & Limpus et al. (1985 in Hanson et al. 1998) \\
\hline & & 30 & Georgia (EUA) & Yntema \& Mrosovsky (1982) \\
\hline & & 29 & Carolina, Geórgia e Flórida (EUA) & Mrosovsky (1988) \\
\hline & & 29,1 & Brasil & Marcovaldi et al. (1997) \\
\hline & & 28,7 & Austrália & Limpus et al. (1983 apud Kaska et al. 1998) \\
\hline & & 28,9 & Austrália e Chipre & Georges et al. (1994), Reece et al. 2002b \\
\hline & & 29 & Turquia e Chipre & Kaska et al. (1998) \\
\hline & Chelonia mydas* & 28,5 a 30 & Costa Rica & Standora \& Spotila (1985) \\
\hline & & 28,8 & Ilha Ascenção & Godley et al. (2002) \\
\hline & & 28,5 a 28,8 & Suriname & Mrosovsky et al. (1984) \\
\hline & & 29,2 & Chipre & Broderick et al. 2000 \\
\hline & & 28,6 & Chipre & Reece et al .2002b \\
\hline & Eretmochelys imbricada* & 29,2 & Antigua & Mrosovsky et al. (1992) \\
\hline & & 29,6 & Bahia (Brasil) & Godfrey et al. (1999) \\
\hline & Lepidochelys kempii & $\sim 30$ & Costa Rica & McCoy et al. (1983) \\
\hline & Lepidochelys olivacea* & 28,5 a 30,5 & Costa Rica & Ruiz et al. (1981 apud Spotila et al. 1987) \\
\hline & & 30 & Costa Rica & McCoy et al. (1983) \\
\hline & & 31 & Costa Rica & Wibbels et al. (1998) \\
\hline & Natator depressus & 29,5 & Queensland (Austrália) & Hewavisenthi \& Parmenter (2000) \\
\hline \multirow[t]{3}{*}{ Dermochelyidae } & Dermochelys coriacea* & 29,5 & Suriname & Mrosovsky et al. (1984) \\
\hline & & 28,7 a 29,7 & Suriname & Rimblot et al. (1985) \\
\hline & & 29,4 & Costa Rica & Binckley et al. (1998) \\
\hline \multicolumn{5}{|c|}{ Tartarugas de água doce } \\
\hline Carettochelyidae & Carettochelys insculpta & & Australia & Georges (1992) \\
\hline \multirow[t]{6}{*}{ Chelydridae } & Chelydra serpentina ${ }^{\ddagger}$ & 20 e 28 a 30 & Wisconsin (EUA) & Yntema $(1976,1979)$ \\
\hline & & 21 e 29 & Wisconsin (EUA) & Yntema (1976) \\
\hline & & 29 & Wisconsin (EUA) & Vogt \& Flores-Villela (1992) \\
\hline & & 25,6 & Flórida (EUA) & Ewert et al. (1994) \\
\hline & & 27 & Veracruz (México) & Vogt \& Flores-Villela (1992) \\
\hline & Macroclemys temminckii ${ }^{\ddagger}$ & 24,4 e 27,1 & Flórida (EUA) & Ewert et al. (1994) \\
\hline Dermatemydidae & Dermatemys mawii & 28 & Veracruz (México) & Vogt \& Flores-Villela (1992) \\
\hline \multirow[t]{16}{*}{ Emydidae } & $\begin{array}{l}\text { Actinemys (Clemmys) } \\
\text { marmorata }\end{array}$ & $\sim 30$ & Oregon e Califórnia (EUA) & Ewert et al. (1994) \\
\hline & Clemmys guttata & $<30$ & Nordeste dos EUA & Ewert et al. (1994) \\
\hline & Chrysemys picta & 20 e 28 a 30 & Tennesse e Wisconsin (EUA) & Bull et al. (1982b) \\
\hline & & 20 e 27,5 & Ontário (Canadá) & Schwarzkopf \& Brooks (1985) \\
\hline & Emys orbicularis & 28,5 & Brenne (França) & Рieau $(1971,1982)$ \\
\hline & Graptemys barbouri & 28,5 & Flórida (EUA) & Ewert et al. (1994) \\
\hline & Graptemys caglei & 29,9 & EUA & Ewert et al. (1994) \\
\hline & Graptemys geographica & 28 a 29 & Wisconsin (EUA) & Bull et al. (1982b) \\
\hline & Graptemys ouachitensis & 28 a 29 & Wisconsin (EUA) & Bull \& Vogt (1979) , Bull et al. (1982b) \\
\hline & temys pseudogeographica & 29 a 29,5 & EUA & Bull et al. (1982b) \\
\hline & & 29 & EUA & Ewert et al. (1994) \\
\hline & Graptemys pulchra & 28 a 29 & Mississippi (EUA) & Bull et al. (1982b) \\
\hline & Graptemys versa & 30,4 & EUA & Ewert et al. (1994) \\
\hline & Trachemys decorata & & & Ewert et al. (2004) \\
\hline & Terrapene ornata & $<29$ & Nebraska (EUA) & Packard et al. (1985) \\
\hline & Trachemys scripta & 29 & Alabama (EUA) & Bull et al. (1982a) \\
\hline
\end{tabular}




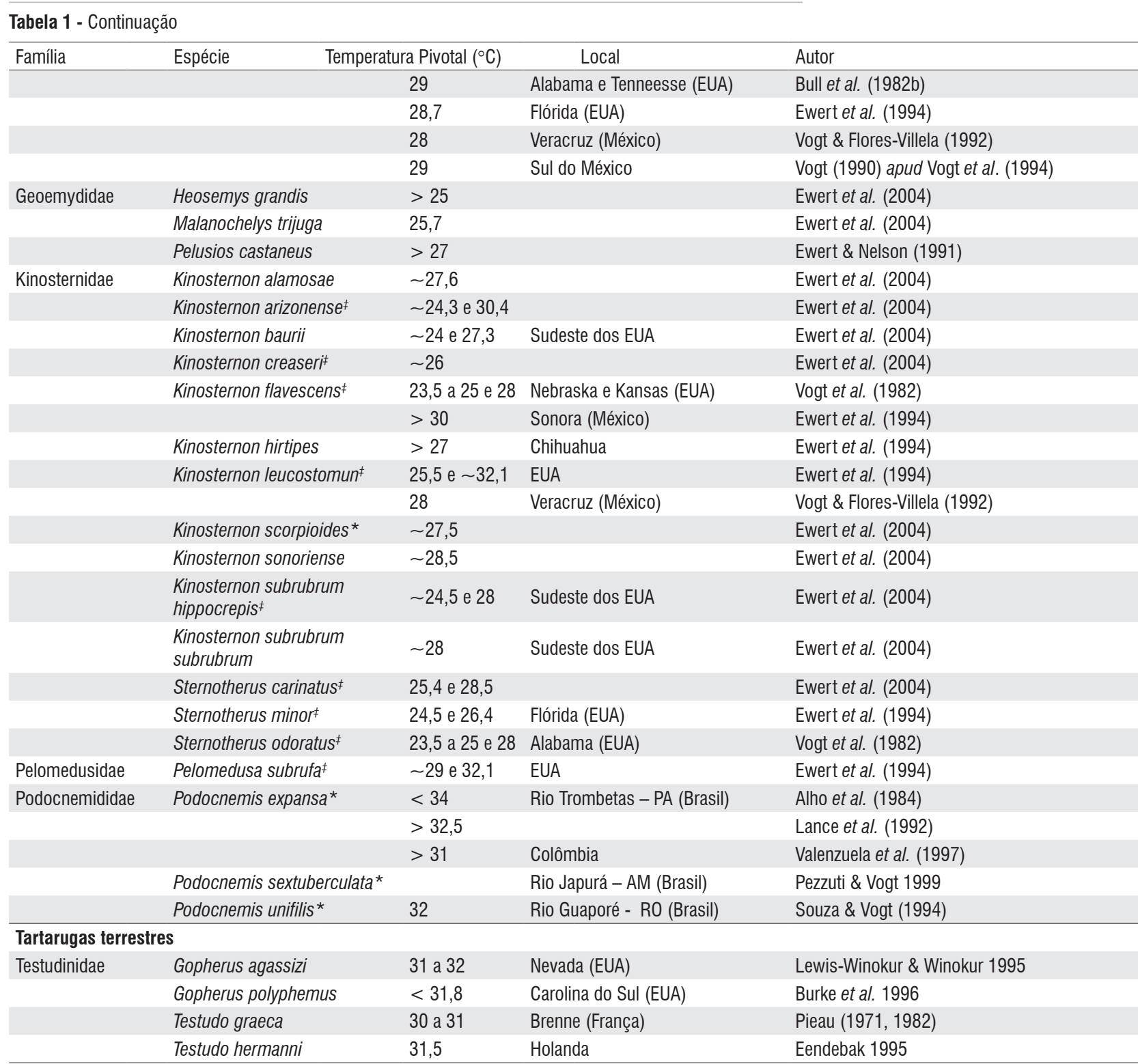

(Charnov \& Bull, 1977). Experimentos conduzidos em laboratório por Conover et al. (1992) mostraram que uma razão sexual francamente favorável a um determinado sexo de Menidia menidia, um peixe marinho comum com DST, pode ser reequilibrada pelas gerações futuras. Variaçōes adaptativas da DST seriam capazes de evoluir em resposta à seleção, como postulado pelo princípio de Charnov-Bull (Bull \& Charnov, 1989; Mrosovsky, 1994).

\section{PADRÕES DA DST E DIMORFISMO SEXUAL}

Ewert \& Nelson (1991) classificaram os padrōes de determinação sexual dos répteis em três tipos:
Padrão Ia: baixas temperaturas de incubação produzem machos e altas temperaturas fêmeas; as fêmeas adultas são maiores que os machos. É exclusivo e o mais comum para tartarugas;

Padrão Ib: baixas temperaturas de incubação geram fêmeas e altas temperaturas machos; os machos são maiores que as fêmeas. É conhecido para lagartos e crocodilianos;

Padrão II: apresenta duas temperaturas pivotais, sendo que baixas e altas temperaturas de incubação geram fêmeas e temperaturas intermediárias machos (Figura 2); machos e fêmeas adultos têm, aproximadamente, o mesmo tamanho. Ocorre em todos os grupos de répteis. 


\begin{tabular}{llll}
\hline \multicolumn{1}{l}{ Tabela 2 - Espécies com determinação sexual genotípica (DSG) (* ${ }^{*}$ espécies brasileiras). } \\
\hline Família & Espécie & Local & Autor \\
\hline Chelidae & Chelodina longicollis & Gungahlin (Austrália) & Georges (1988) \\
& Elseya novaguineae & & Ewert et al. (2004) \\
& Elusor macrurus & & Georges \& Mclnnis (1998) \\
& Emydura macquari & Barmera (Austrália) & Thompson (1988a) \\
& Emydura signata & New South Wales (Austrália) & Bull et al. (1985) \\
& Emydura subglobosa & & Ewert et al. (2004) \\
& Mesoclemys gibba* & & Ewert et al. (2004) \\
& Phrynops geoffroanus* & Rio Guaporé - RO (Brasil) & Vogt (1992), Ewert et al. (2004) \\
\hline Emydidae & Phrynops hilarii* & & Ewert et al., (2004) \\
\hline Kinosternidae & Glyptemys (Clemmys) insculpta & Michigan (EUA) & Bull et al. (1985) \\
& Claudius angustatus & Veracruz (México) & Vogt \& Flores-Villela (1992) \\
\hline Podocnemididae & Staurotypus triporcatus & Veracruz (México) & Vogt \& Flores-Villela (1992) \\
\hline Trionychidae & Peltocephalus dumeriliana* & Rio Trombetas - PA (Brasil) & Vogt et al. (1994) \\
& Apalone mutica & & Valenzuela \& Shikano (2007) \\
& Apalone spinifera & Wisconsin (EUA) & Bull \& Vogt (1979) \\
\hline
\end{tabular}

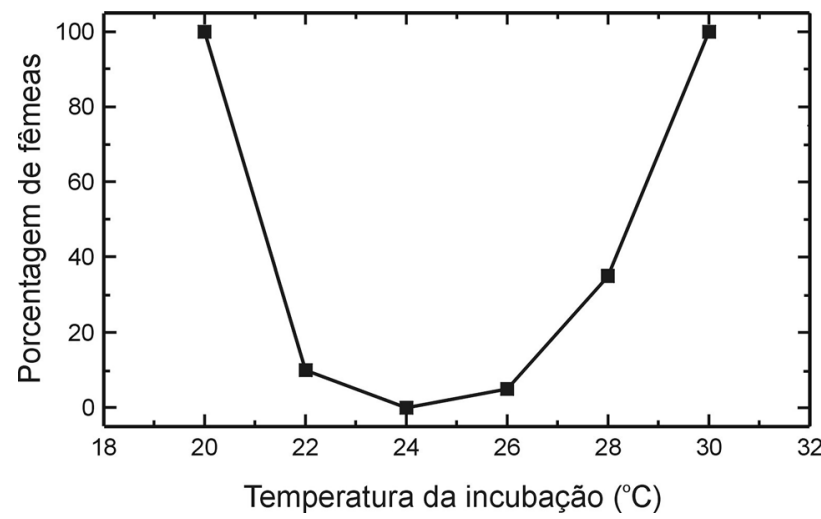

Figura 2 - Relação entre a temperatura de incubação e a razão sexual de Chelydra serpentina (Yntema, 1978). Machos são gerados em temperaturas intermediárias e fêmeas em temperaturas altas e baixas, 0 que caracteriza 0 padrão II (Ewert et al., 1994).

O padrão II, segundo Head et al. (1987), ocorre em espécies cujos ovos experimentam grandes variaçōes de temperatura de incubação ou que apresentam uma grande abrangência geográfica como é o caso de C. picta (Bull et al., 1982a), de C. serpentina (Bobyn \& Brooks, 1994) e de Sternotherus minor (Ewert et al., 1994). Em Sternotherus odoratus e Kinosternon flavescens a presença de duas temperaturas pivotais, uma a 28 ${ }^{\circ} \mathrm{C}$ e a outra a $23^{\circ} \mathrm{C}$ possibilita a manutenção de uma razão sexual equilibrada em regióes de altas latitudes. Na Flórida (EUA), estas espécies desovam ao longo de todo o ano e o padrão de DST do tipo II facilita o equilíbrio da razão sexual (Vogt et al., 1982).

A DST em répteis foi parcialmente justificada com base no dimorfismo entre os animais adultos (Head et al., 1987). A base deste raciocínio está na constatação que os filhotes gerados nas temperaturas de incubação mais elevadas nascem maiores, crescem mais rápido e tornam-se adultos de maior porte. Crocodilos (padrão Ib) machos são maiores que as fêmeas, refletindo a importância das competiçōes pelo acasalamento. No geral, as tartarugas (padrão Ia) fêmeas adultas são maiores que os machos e as disputas territoriais não são intensas como nos crocodilos. Fêmeas maiores também apresentam maiores desovas. Algumas espécies de quelônios como C. serpentina apresentam duas temperaturas pivotais com machos sendo gerados em temperaturas intermediárias, mas o dimorfismo sexual premia os machos com um maior tamanho e uma maior agressividade, assim como os crocodilos.

\section{CORRELAÇÃO ENTRE A RAZÃO SEXUAL E A TEMPERATURA DE INCUBAÇÃO}

Desde o momento que se descobriu a DST (Charnier, 1966; Pieau, 1971, Yntema, 1976), tem-se buscado definir e quantificar o momento e os níveis de temperatura que afetam a diferenciação das gônadas sexuais. Yntema \& Mrosovsky (1982) afirmaram que a temperatura média de toda a incubação não deve ser utilizada para explicar a razão sexual, pois o importante é a temperatura experimentada pelos embriôes durante o período termo-sensitivo. A temperatura experimentada pelos ovos antes e depois do período termosensitivo pode afetar a taxa de desenvolvimento, mas não terá efeito sobre a definição do sexo dos embriōes.

Em laboratório, sob temperaturas constantes, o período termo-sensitivo coincide com o segundo terço da incubação. Entretanto, para os ninhos incubados no ambiente natural essa correlação sem sempre é verificada, pois mudanças abruptas no clima ou chuvas intensas podem alterar a taxa 
de desenvolvimento embrionário deslocando o momento quando o sexo é definido (Georges et al., 2004). A taxa de desenvolvimento embrionário é maior nos períodos de alta temperatura que nos períodos de temperaturas mais baixas. Dessa forma vai ocorrer um maior desenvolvimento embrionário em altas temperaturas (Bull \& Vogt, 1981; Pieau, 1982; Mrosovsky et al., 1984). Se um embrião for incubado em um ninho natural cuja temperatura média coincide com a pivotal, devido as variaçōes diárias, ele passará 50\% do tempo abaixo da temperatura média e $50 \%$ acima da temperatura média. Entretanto, a maior parte do desenvolvimento embrionário ocorrerá acima da temperatura média, pois a taxa de desenvolvimento correlaciona-se positivamente com a temperatura. Dessa forma, o sexo dos filhotes dependerá mais da proporção relativa do desenvolvimento embrionário que ocorreu acima ou abaixo da temperatura pivotal que do tempo a que os embriōes foram expostos a temperaturas acima ou abaixo da temperatura pivotal (Georges, 1989; Georges et al., 2004).

A correlação entre a temperatura média da incubação durante o período termo-sensitivo e a razão sexual foi constatada nas tartarugas marinhas C. caretta (Yntema \& Mrosovsky, 1982; Maxwell et al., 1988; Kaska et al., 1998), C. mydas (Kaska et al.; 1998, Godley et al., 2002; Reece et al. 2002a), D. coriacea (Rimblot et al., 1985), nas tartarugas de água doce Graptemys (Bull \& Vogt, 1979), C. picta (Gutzke \& Paukstis, 1984), Emys orbicularis (Pieau \& Dorizzi, 1981), S. odoratus e K. flavescens (Vogt et al., 1982) e nas tartarugas terrestres Testudo graeca (Pieau, 1971), Testudo hermanni (Eendebak, 1995), Gopherus agassizi (Lewis-Winokur \& Winokur, 1995) e Gopherus polyphemus (Burke et al., 1996). Estes resultados são válidos principalmente para os experimentos conduzidos com temperaturas controladas. Em ninhos naturais, onde a temperatura é variável, a temperatura média diária da incubação não é uma boa ferramenta preditiva da razão sexual dos filhotes (Weisrock \& Janzen, 2000). Vários autores relatam ausência de correlação entre a temperatura média do período termo-sensitivo e a razão sexual de Emys orbicularis (Pieau, 1982), da tartaruga-da-amazônia Podocnemis expansa (Valenzuela et al., 1997; Malvasio et al., 2002) e do tracajá Podocnemis unifilis (Souza \& Vogt, 1994). Pequenas variaçôes em torno da temperatura pivotal podem afetar a diferenciação das gônadas. Como exemplo, Mrosovsky et al. (1992) cita a incubação de Eretmochelys imbricata onde curtos intervalos com temperatura acima da temperatura pivotal foram suficientes para gerar uma razão sexual favorável a fêmeas de ovos submetidos a temperaturas abaixo da temperatura pivotal a maior parte do tempo.

Em ninhos naturais, a razão sexual de $C$. picta foi explicada pelo número de horas gastas acima e abaixo da temperatura pivotal (Schwarzkopf \& Brooks, 1985). A razão sexual de $P$. unifilis foi explicada com base no número de horas acima da temperatura pivotal durante o período termo-sensitivo (Souza $\&$ Vogt, 1994), enquanto que para P. expansa, a razão sexual foi ao "número de horas acima de $31^{\circ} \mathrm{C}$ entre os dias 29 e $30 \mathrm{da}$ incubação" (Valenzuela et al., 1997). Cada um desses exemplos acima é uma adequação a uma situação específica. Buscando uma generalização Georges et al. (1994) propuseram, com base em um modelo matemático, que a razão sexual dos filhotes de C. caretta depende da proporção diária do desenvolvimento acima da temperatura pivotal. Este modelo, contudo, necessita ser testado em outras espécies, mas é incontestável que a taxa de desenvolvimento embrionário nas espécies com DST é uma função direta da temperatura de incubação.

\section{DST E A DISTRIBUIÇÃO GEOGRÁFICA DAS ESPÉCIES DE TARTARUGA}

Tartarugas marinhas apresentam uma ampla distribuição geográfica. Entretanto a temperatura pivotal das espécies apresenta valores muito próximos (Tabela 1), variando de 28 ${ }^{\circ} \mathrm{C}$ a $30{ }^{\circ} \mathrm{C}$ (Mrosovsky, 1994; Wibbels et al., 1998; Godley et al., 2002; Reece et al., 2002b). Variaçôes latitudinais e, consequentemente, das condições climáticas não alteram a temperatura pivotal (Mrosovsky, 1988), devido ao fluxo de genes entre as populaçôes (Binckley et al. 1998). Para tartarugas marinhas, tanto as variaçôes intra-espécies (até 1,5 ${ }^{\circ} \mathrm{C}$ para C. mydas) quanto as variaçôes interespécies (até $2,5^{\circ} \mathrm{C}$ entre C. mydas e Lepidochelys olivacea) da temperatura pivotal são consideradas baixas.

Para tartarugas de água doce, a variação da temperatura pivotal intra-espécie e interespécie é grande (Ewert et al., 1994, 2004). Ao longo das espécies com DST do padrão Ia, a temperatura pivotal varia de $27,5^{\circ} \mathrm{C}$ para $C$. picta (Schwarzkopf \& Brooks, 1985) a 32,5-34 ${ }^{\circ} \mathrm{C}$ para P. expansa (Alho et al., 1985; Lance et al., 1992). No padrão II a temperatura varia de $25,6^{\circ} \mathrm{C}$ em Kinosternon leucostomum a aproximadamente $32,1^{\circ} \mathrm{C}$ em Pelomedusa subrufa (Ewert et al., 1994). As variaçōes intra-espécie da temperatura pivotal são influenciadas pela distribuição geográfica como exemplificado para C. picta (Schwarzkopf \& Brooks, 1985) e Graptemys (Bull et al., 1982b). A variação da temperatura pivotal em espécies com grande abrangência geográfica e baixo fluxo de genes parece ser um artifício que evita uma razão sexual tendendo para um determinado sexo (Bull et al., 1982b).

A faixa de temperatura na qual a incubação dos ovos é viável funciona como um componente que limita a distribuição geográfica de Emys orbicularis (Servan et al., 1989) e Emydoidea blandingii (Standing et al., 1999, 2000a). Próximo ao limite inferior da temperatura a mortalidade dos embriōes é muito alta e os filhotes freqüentemente morrem após a eclosão (Yntema, 1978; Ewert \& Nelson, 1991; Bobyn \& Brooks, 1994). Segundo Standing et al. (2000a) a população 
de E. blandingii na Nova Escócia, Canadá, no limite norte da distribuição da espécie, apresenta um baixo sucesso de eclosão e os filhotes são de "baixa qualidade". O crescimento e a sobrevivência dos filhotes incubados a temperaturas muito baixas também é menor no primeiro ano de vida (McKnight \& Gutzke 1993; Bobyn \& Brooks, 1994). Baixas temperaturas de incubação induzem problemas em tartarugas, tais como, deformaçôes morfológicas ou problemas neurológicos (Ewert \& Nelson, 1991; Bobyn \& Brooks, 1994; Standing et al., 1999).

\section{INFLUÊNCIA DAS CARACTERÍSTICAS DOS NINHOS NO DESENVOLVIMENTO EMBRIONÁRIO}

Modelos teóricos mostram que nas espécies com DST a razão sexual é governada por dois fatores (Bull, 1980; Janzen \& Morjan, 2001): a) sensitividade termal do embrião e b) escolha maternal das qualidades termais do local de desova. As características do habitat e o microambiente dos ninhos estão ligados e têm conseqüências no desenvolvimento dos embriōes e filhotes (Weisrock \& Janzen, 2000). O local da nidificação terá influência decisiva no ambiente hídrico e termal dos ninhos, afetando ainda as trocas gasosas entre a câmara de ovos e o meio (Ackerman, 1980). O local de desova poderá afetar a taxa de predação (Ferreira Júnior et al., 2003a) e a razão sexual das espécies com DST.

Vários são os elementos atribuídos como potenciais indicadores seletivos das áreas de desova das tartarugas marinhas, tais como, a salinidade (Johannes \& Rimmer, 1984 apud Garmestani et al. 2000), a temperatura (Stoneburner \& Richardson, 1981), o conteúdo de bioclastos, o pH, a umidade, o conteúdo de matéria orgânica (Stancyk \& Ross, 1978; Mortimer, 1990), a cobertura vegetal (Hays \& Speakman, 1993; Wang \& Cheng, 1999), a largura da praia (Kikukawa et al., 1999; Garmestani et al., 2000), o albedo (Hays et al., 2001), as variaçôes na temperatura do solo (Stoneburner \& Richardson, 1981) e a proximidade com a foz dos rios (Baptistotte et al. 2003). Estes elementos, além de influenciarem a escolha dos locais de desova, podem afetar o sucesso da eclosão (Hays \& Speakman, 1993; Horrocks \& Scott, 1991; Ferreira Júnior et al., 2003b) e a razão sexual dos filhotes (Vogt \& Bull, 1984; Mrosovsky \& Provancha, 1989).

Praias com diferentes taxas de eclosão apresentam maior concentração de ninhos nos pontos onde o sucesso da eclosão é maior (Horrochs \& Scott, 1991; Hays \& Speakman, 1993). Por outro lado, $P$. expansa e $P$. unifilis privilegiam locais onde a temperatura de incubação é maior apesar de estes locais propiciarem um menor sucesso da eclosão (Ferreira Júnior \& Castro, 2003, 2005). Segundo Godley et al. (2001), o sucesso da eclosão correlaciona-se à temperatura da incubação, sendo menor a altas temperaturas. Entender como esses elementos interagem é fundamental à compreensão dos fatores que regem a embriogênese e a determinação sexual dos quelônios.

Ninhos de C. mydas situados em áreas vegetadas têm menor temperatura de incubação (Standora \& Spotila, 1985), apresentando 7,4\% de fêmeas, ao passo que de ninhos situados em locais ensolarados emergem $83,5 \%$ de fêmeas (Spotila et al., 1987). O mesmo ocorre com C. caretta (Foley et al., 2000). Chelonia mydas e E. imbricata desovam com freqüência nas partes mais altas da praia sob arbustos e árvores onde a temperatura das camadas superficiais do solo é mais baixa (Wang \& Cheng, 1999). Dermochelys coriacea utiliza, normalmente, a zona aberta da praia desprovida de vegetação onde a temperatura dos ninhos, em relação ao local de desova, é praticamente a mesma ao longo de toda a temporada reprodutiva (Godfrey et al., 1996). Mrosovsky et al. (1984) não encontraram diferenças significativas da temperatura a $60 \mathrm{~cm}$ de profundidade, indicando que a temperatura de incubação é praticamente a mesma nos ninhos ensolarados e sombreados.

O tamanho e a coloração dos sedimentos afetam a temperatura dos ninhos de Caretta caretta (Naro-Maciel et al., 1999). Ninhos localizados em sedimentos mais grossos de coloração amarela apresentam temperaturas mais elevadas que ninhos situados em sedimentos finos e brancos. $\mathrm{O}$ albedo seria o responsável por essas diferenças de temperatura e durante o dia os ninhos de C. mydas situados em áreas com sedimentos escuros são submetidos a maiores temperaturas que aqueles localizados em areias mais claras (Hays et al., 2001). As temperaturas mais baixas encontradas nas areias mais escuras raramente são inferiores às temperaturas mais altas das areias claras. Desta forma, a cor do sedimento e, conseqüentemente o albedo, pode influenciar a determinação sexual dos filhotes de tartaruga marinha. Esta afirmação, apesar de ter sido acolhida sem ressalvas, deve ser analisada com certo cuidado, pois o tamanho do sedimento pode estar atuando em conjunto com o albedo na determinação da temperatura junto aos ninhos e a cor do sedimento pode variar com o seu tamanho e composição mineralógica (Ferreira Júnior, 2003; Ferreira Júnior et al. 2003b). Areias de praias fluviais e marinhas retrabalhadas pelo vento são mais claras, mais finas e com melhor seleção granulométrica que aqueles sedimentos que não foram transportados pelo vento e que são mais grossos, mal selecionados e escuros.

A vegetação de supralitoral não influencia a escolha das áreas de nidificação de C. caretta (Garmestani et al., 2000), mas a presença de pequenas raízes e umidade aumenta a coesão da areia, facilitando a abertura dos ninhos por C. mydas (Bustard \& Greenham, 1968).

Para algumas espécies de tartarugas terrestres e de água doce, a escolha dos locais de desova parece ser mais evidente que para tartarugas marinhas (Bodie et al., 2000) e 
a cobertura vegetal terá uma importância decisiva na escolha dos sítios de nidificação e na razão sexual dos filhotes. Para espécies com DST como Graptemys ouachitensis e Graptemys pseudogeographica (Vogt \& Bull, 1984), Chrysemys picta belli (Janzen, 1994) e P. expansa (Alho et al., 1984), ninhos localizados em áreas vegetadas e sombreadas geram mais machos. O sucesso da eclosão de P. unifilis (Escalona \& Fa, 1998), K. baurii (Wilson, 1998) e E. blandingii (Congdon et al., 2000) também é afetado pelo grau de sombreamento dos ninhos. Weisrock \& Janzen (2000) não encontraram relação entre a cobertura vegetal e a razão sexual de $C$. picta.

As estratégias reprodutivas e os locais de desova variam ao longo das espécies e as características do canal fluvial são importantes na distribuição das espécies (Donner Wright et al. 1999). Para diversas espécies de tartaruga de água doce com DST a escolha dos locais de desova recai, normalmente, sobre praias abertas e arenosas e elas podem procurar habitats alternativos como ombreiras (levees) quando seus locais históricos não estão disponíveis (Bodie, 2001). Chrysemys picta é apontada como uma exceção, pois prefere solos argilosos para desovar (Legler, 1954), mas a distribuição dos ninhos é proporcional à área ocupada por cada tipo de solo e não há um critério seletivo nesta informação (Christens \& Bider, 1987). Podocnemis uniflis é uma das espécies menos seletivas, desovando em praias arenosas, em solos areno-argilosos das margens de lagos e no meio da vegetação (Ferreira Júnior, 2003). De acordo com Standing et al. (2000b), E. blandingii desova nas praias abertas e arenosas onde o sucesso da eclosão é maior.

As tartarugas de água doce Phrynops raniceps, Phrynops geoffroanus e Chelus fimbriatus desovam em terra firme, entrando até $200 \mathrm{~m}$ no meio da floresta (Vogt, 1992). Estas espécies que compartilham os rios com $P$. expansa e $P$. unifilis apresentam uma maior duração de incubação. A diferença entre o local de desova destas espécies pode estar associada ao tipo da determinação sexual. Phrynops geoffroanus, que desova em locais sombreados e frios, possui DSG (Vogt, 1992), ao passo que $P$. expansa e $P$. unifilis que desovam em locais abertos e ensolarados (Ferreira Júnior \& Castro, 2003, 2005) são DST. Outras espécies neotropicais com larga duração da incubação, semelhante a $P$. geoffroanus como Staurotypus triporcatus, Claudius angustatus e Peltocephalus dumerilianus também apresentam DSG e, aparentemente, não são seletivas na escolha das áreas de desova (Vogt et al., 1994; Vogt \& Flores-Villela, 1992).

O tamanho do quelônio também deverá influenciar a escolha do local de nidificação, pois indivíduos maiores escavam ninhos mais profundos onde as variações da temperatura são menores (Burger, 1976b; Packard \& Packard, 1988; Thompson, 1988b). Espécies de médio e grande porte como C. serpentina (Petokas \& Alexandre, 1980), Podocnemis sextuberculata (Pezzuti \& Vogt, 1999), P. expansa (Alho et al., 1985; Ferreira Júnior \& Castro 2003) e Apalone mutica (Plummer et al., 1994) preferem desovar em áreas abertas e arenosas, mas apresentam ninhos mais profundos. Espécies pequenas como K. baurii (Wilson, 1998), que desovam em ninhos rasos, evitam áreas abertas ou escolhem locais com uma maior umidade. $\mathrm{O}$ sombreamento ou a maior umidade podem impedir temperaturas muito elevadas que seriam fatais aos embriões (Wilson, 1998; Ferreira Júnior, 2003). Congdon et al. (2000) mostraram que nos locais sombreados a temperatura dos ninhos de E. blandingiié $6,3^{\circ} \mathrm{C}$ mais baixa que nas áreas ensolaradas.

Existe uma forte relação entre a razão sexual e a profundidade dos ninhos de C. picta (Schwarzkopf \& Brooks, 1987). De acordo com Wilhoft et al. (1983) ocorre uma estratificação da razão sexual de C. serpentina em um mesmo ninho devido ao posicionamento dos ovos. Na parte superior do ninho, exposta a temperaturas mais elevadas, são geradas fêmeas. Com o aumento da profundidade e diminuição da temperatura, mais machos são produzidos.

Krause et al. (1982) assinalaram que as camadas inferiores e superiores dos ninhos de Trachemys dorbigni, geralmente, são compostas por ovos inviáveis possivelmente por causa de grandes variaçōes do ambiente hídrico e termal. Para $C$. caretta, a profundidade do ninho poderá afetar o sucesso da eclosão. Os ovos da parte superior são naturalmente expostos a maiores temperaturas o que pode ocasionar uma maior mortalidade dos embriões (Ferreira Júnior et al., 2003b). Segundo Ackerman (1991 apud Packard, 1999), a umidade do solo varia intensamente em profundidade e os ovos do topo, do meio e da base dos ninhos estarão sujeitos a diferentes regimes de umidade.

Burger (1976a) observou que a temperatura dos ninhos de Malaclemys terrapin terrapin varia diariamente e a posição do ninho em uma duna pode ocasionar uma diferença significativa em termos de radiação solar recebida e, por conseguinte, da temperatura final experimentada pelos ovos. Espécies de tartaruga de água doce, G. barbouri, S. minor e T. scripta de regiōes mais quentes, escolhem áreas sombreadas para desovarem, enquanto que Macroclemys temminckii, de regiōes mais frias, procuram pontos abertos e ensolarados, o que pode ser uma maneira de atingir uma razão sexual equilibrada em regióes com características climatológicas distintas (Ewert et al., 1994). Chrysemys picta utiliza o mesmo microambiente em sucessivas desovas, o que confirmaria a teoria que as fêmeas podem "controlar" a razão sexual dos filhotes através da escolha do ambiente termal dos ninhos e esse controle deve ser hereditário (Janzen \& Morjan, 2001).

Moll (1994) relatou que Trachemys scripta venusta, uma tartaruga de água doce, entra no mar e desova nas praias oceânicas do Mar do Caribe. A fase marinha da nidificação 
foi interpretada como uma adaptação à forte pressão seletiva para minimizar os riscos de predação dos animais adultos e de seus ovos. A diversidade e o número de predadores na floresta e nas margens dos rios e dos lagos são maiores que nas praias oceânicas. O local escolhido para a desova por T. s. venusta é o mais alto da praia e coberto por uma vegetação rasteira (berma) que fornece abrigo e condiçôes adequadas de temperatura para a incubação. A praia aberta e a zona com vegetação alta e densa são evitadas pela espécie, pois nestes locais as temperaturas são impróprias ao desenvolvimento embrionário.

Em outros grupos de répteis com DST também se observa uma escolha maternal por determinados sítios de desova. A razão sexual em crocodilianos varia em função da localização do ninho. Em Alligator mississippiensis são gerados mais machos nos ninhos situadas nas ombreiras dos rios (mais quentes) e fêmeas nos pântanos (Ferguson \& Joanen, 1989). Em Crocodylus palustris, os primeiros ninhos da temporada reprodutiva situam-se em locais quentes e ensolarados e as últimas desovas são realizadas na sombra (Lang et al., 1989). Esta observação sugere que as fêmeas escolhem um local com características termais próprias e este comportamento muda sazonalmente, aumentando o sucesso da eclosão. Os lagartos com DST Eublepharis macularius e Hemitheconyx caudicinctus desovam em locais com temperaturas intermediárias, e o lagarto Coleonyx mitratus que possui DSG não tem nenhum sítio de nidificação preferencial (Bull et al. 1988; Bragg et al., 2000). Condiçōes hídricas e termais adequadas à incubação são responsáveis pela distribuição geográfica do iguana do deserto Dipsosaurus dorsalis (Muth, 1980).

Assim como a temperatura, a umidade do solo varia com a profundidade e é apontada como um importante critério de seleção das áreas de desova (Ferreira Júnior et al., 2007). Fowler (1979) sugere que os locais escolhidos pelas tartarugas marinhas visam evitar a erosão dos ninhos ou a sua inundação pelas marés altas e pelo lençol freático. A desova de C. caretta (Kraemer \& Bell, 1980) e C. mydas (Mortimer, 1990) ocorre preferencialmente no alto das dunas o que pode evitar o alagamento dos ninhos durante grandes chuvas. Dunas constituídas de areia quartzosa fina com alto conteúdo de sal inibem a penetração da água da chuva (Kraemer \& Bell, 1980). O alagamento dos ninhos pode causar a morte dos embriōes pelo sufocamento (Kraemer \& Bell, 1980; Plummer, 1976) ou à exposição a altas salinidades (Bustard \& Greenham, 1968). Nas praias do sul do Espírito Santo, onde o alagamento dos ninhos é insignificante, a desova de C. caretta ocorre de maneira indistinta tanto na praia aberta quanto na berma situada acima da linha de maré alta (Ferreira Júnior et al., 2003b).

Apesar de nidificarem em uma mesma praia, $D$. coriacea e C. mydas escolhem ambientes distintos. Dermochelys coriacea desova em uma área mais aberta, arenosa, sem vegetação, próxima do mar, abaixo da linha de alta maré (Mrosovsky, 1983), ao passo que C. mydas, geralmente, escolhe pontos mais altos, afastados da linha de costa, com vegetação esparsa, acima da linha de maré alta (Whitmore \& Dutton, 1985). Bjorndal \& Bolten (1992), entretanto, não verificaram este padrão de distribuição dos ninhos. Possivelmente devido as suas grandes dimensões e dificuldades de locomoção em terra, $D$. coriacea não escolhe um ponto em particular em relação à distância da linha de costa para desovar (Eckert, 1987). Por outro lado, as áreas de desova situam-se próximas de um litoral com acesso mais profundo, sem a presença de bioconstruçōes ou barreiras rochosas ou arenosas nas suas imediaçôes o que, aparentemente, facilita a livre circulação destas grandes tartarugas marinhas. A granulometria mais fina dos sedimentos, em associação com a umidade e presença de pequenas raízes é apontada como um critério de seleção das áreas de desova, pois facilita a abertura dos ninhos de $C$. mydas (Mortimer \& Carr, 1987; Mortimer, 1990) e D. coriacea (Whitmore \& Dutton, 1985).

As tartarugas marinhas C. caretta (LeBuff \& Beatty, 1971), C. mydas (Carr \& Carr, 1972; Carr, 1975; Bjorndal \& Bolten, 1992) e D. coriacea (Godfrey et al., 1996) nem sempre retornam ao mesmo local das desovas anteriores, o que dificulta o estabelecimento de um possível padrão de distribuição dos ninhos. As tartarugas que retornam à mesma praia de desova, nem sempre escolhem um local com características fisiográficas ou um ambiente hídrico e termal similar (Carr \& Carr, 1972). Processos sedimentares, ao longo de 10 anos, deslocaram a praia de Matapica, no Suriname em cerca de $20 \mathrm{~km}$ e as tartarugas marinhas $D$. coriacea e $C$. mydas continuaram desovando na "mesma" praia (Godfrey et al., 1996).

Milton et al. (1997) mostraram a influência da composição mineralógica na temperatura dos ninhos de $C$. caretta nas praias da Florida (EUA). A temperatura dos ninhos situados em sedimentos quartzosos foi de $3,4^{\circ} \mathrm{C}$ mais alto que nos ninhos localizados em sedimentos carbonáticos. A diferença de temperatura entre os ninhos de composição mineralógica distinta é significante no topo, no meio e na base da câmara de ovos. A duração da incubação também foi afetada pela composição mineralógica dos sedimentos. Ninhos situados em sedimentos quartzosos apresentaram uma duração de incubação menor que aqueles localizados em sedimentos de composição carbonática. Milton et al. (1997) concluíram que os projetos que envolvam a transferência de ninhos devem considerar a composição mineralógica das praias e dos berçários.

Alguns autores discordam da influência das características físicas das praias na escolha dos locais de desova de tartarugas marinhas (Stancyk \& Ross, 1978) e de tartarugas de água doce (Petokas \& Alexander, 1980; Pezzuti \& Vogt, 1999) ou no 
sucesso da eclosão ou na razão sexual dos filhotes (Maxwell et al., 1988). Porém mesmo que a temperatura de incubação dos ninhos de tartaruga marinha varie pouco nos ambientes tropicais (Spotila et al., 1987; Mrosovsky et al., 1984), já que a profundidade e os locais escolhidos pelas fêmeas minimizam os efeitos do ambiente (Binckley et al., 1998), é inegável a influência que o local de desova terá no sucesso da eclosão (Ferreira Júnior et al., 2003b; Ferreira Júnior \& Castro, 2005) e na razão sexual dos filhotes (Hays et al., 2001).

Os resultados de uma dada população não devem ser extrapolados para toda a espécie, pois as características reprodutivas variam com a posição geográfica e o tempo (Tinkle et al., 1981; Etchberger \& Ehrhart, 1987; Iverson et al. 1993). A desova de Clemmys guttata, E. blandingii, S. odoratus, G. geographica e C. serpentina em Ontário no Canadá ocorre sobre afloramentos rochosos. A escolha deste local, que é o mais quente da área, deve-se ao fato do afloramento rochoso receber insolação direta, aquecendo-se mais rapidamente e mantendo as temperaturas elevadas (Litzgus \& Brooks, 2000). A desova em áreas sombreadas não garantiria temperaturas suficientes ao desenvolvimento embrionário (Bobyn \& Brooks, 1994). Para populações destas mesmas espécies que ocupam áreas em menores latitudes, a desova ocorre em outras áreas e em ambientes distintos (Ernst, 1970). Este fato sugere que algumas espécies alteram o local de desova ao longo da sua área de ocorrência objetivando garantir a incubação dos ovos e um maior sucesso da eclosão.

\section{CONHECIMENTO BRASILEIRO DOS MECANISMOS DA DETERMINAÇÃO SEXUAL}

Para as tartarugas brasileiras são identificadas duas situações distintas no que diz respeito ao conhecimento do mecanismo responsável pela determinação sexual. No primeiro grupo, situam-se as cinco espécies de tartarugas marinhas que desovam no litoral brasileiro e para as quais a temperatura pivotal já foi determinada. Destaque para os trabalhos com populações brasileiras de Caretta caretta (Marcovaldi et al., 1997; Mrosovsky et al., 1999) e Eretmochelys imbricata (Godfrey et al., 1999) que apresentam a duração pivotal da incubação que permite estimar a razão sexual com base no número de dias de incubação. Para as outras espécies (Lepidochelys olivacea, Chelonia mydas e Dermochelys coriacea) já foram calculadas as temperaturas pivotais em outras partes do mundo. Como a temperatura pivotal das tartarugas marinhas apresenta valores muito próximos ao longo de suas diversas áreas de desova (Mrosovsky et al., 1984; Marcovaldi et al., 1997; Binckley et al., 1998, Chevalier et al., 1999; Godley et al., 2002) a falta dessa informação, para o litoral brasileiro, aparentemente, não trás grandes problemas para as iniciativas de preservação das espécies.
No segundo grupo, enquadram-se as espécies terrestres e de água doce (SBH, 2007). Para os jabutis Geochelone carbonaria e Geochelone denticulata ainda não existem informaçōes seguras acerca do modo de determinação do sexo ou da temperatura pivotal. Apenas G. carbonaria foi testado com indicações de que a determinação sexual é dependente da temperatura de incubação (Franco, 1994). Devido à ampla distribuição geográfica dessas espécies que ocupam diferentes biomas é importante que se estabeleça o modo da reprodução e possíveis variaçôes da temperatura pivotal, pois essas informaçōes podem auxiliar o estabelecimento de áreas prioritárias de conservação e estratégias de manejo. Para as 29 espécies de tartaruga de água doce, oito já foram testadas, sendo que quatro apresentam determinação sexual dependente da temperatura de incubação (Podocenmis sextuberculata, $P$. unifilis e $P$. expansa, pertencentes à família Podocnemididae e Kinosternon scorpioides da família Kinosternidae) e nas outras quatro a definição do sexo independe da temperatura da incubação (Phrynops geoffroanus, Mesoclemmys gibba, P. hilarii da família Chelidae e Peltocephalus dumeriliana da família Podocnemididae). Para Kinosternon scorpioides os dados são ambíguos (Ewert et al., 2004) e estudos complementares são necessários para se determinar a temperatura pivotal. Faltam estudos com 17 outras espécies da família Chelidae, com Rhinoclemmys punctularia (Geoemydidae), Trachemys adiutrix e T. dorbigni (Emydidae) e Podocnemis erythrocephala (Podocnemididae). A família Podocnemididae é a melhor estudada e $P$. expansa apresenta a maior temperatura pivotal entre todos os répteis, superior a $34{ }^{\circ} \mathrm{C}$ para a população do rio Trombetas (Alho et al., 1994).

A determinação do modo da reprodução deve ser realizada para todas as espécies, pois dentro de uma mesma família (e.g. Podocnemididae, Emydidae e Kinosternidae) podem conviver os dois modos de determinação sexual (Janzen \& Krenz, 2004; Ewert et al., 2004). O trabalho inicial mais apropriado para esse tipo de estudo é em laboratório onde as condiçóes de temperatura são controladas. A extensão para ninhos naturais também é essencial para que se conheça a influência que o local da desova exerce na temperatura pivotal.

Para as espécies com grande distribuição geográfica a temperatura pivotal deve ser analisada em mais de uma região, pois podem ocorrer variaçōes buscando manter o equilíbrio das populaçōes (Ewert et al., 1994, 2004). Essas informações são valiosas na elaboração de planos e estratégia de conservação e utilização racional dos quelônios brasileiros. $\mathrm{O}$ estabelecimento do modo de determinação sexual e da temperatura pivotal também possibilita uma avaliação mais segura da efetividade de algumas práticas de manejo, principalmente aquelas que envolvem a transferência de ninhos (Naro-Maciel et al., 1999). Sempre que possível é desejável que a transferência de ninhos se dê para locais que 
possuam características fisiográficas semelhantes ao local de origem para que a razão sexual seja mantida.

\section{AGRADECIMENTO}

Este artigo foi elaborado com base na tese de doutorado do autor, realizada no Departamento de Geologia da Universidade Federal de Ouro Preto e contou com bolsa de estudos da CAPES. Agradecimentos especiais a P.T.A. Castro pela orientação durante as pesquisas e a R.C. Vogt pelo incentivo à publicação.

\section{BIBLIOGRAFIA CITADA}

Ackerman, R.A. 1980. Physiological and ecological aspects of gas exchange by sea turtle eggs. Am. Zool., 1980(5): 575-583.

Alho, C.J.R.; Danni, T.M.S.; Pádua, L.F.M. 1984. Influência da temperatura de incubação na determinação do sexo da tartarugada-amazônia (Podocnemis expansa, Testudinata: Pelomedusidae). Rev. Bras. Biol., 44(3): 305-311.

Alho, C.J.R.; Danni, T.M.S.; Pádua, L.F.M. 1985. Temperaturedependent sex determination in Podocnemis expansa (Testudinata: Pelomedusidae). Biotropica, 17(1): 75-78.

Baptistotte, C.; Thomé, J.C.A.; Bjordnal, K.A. 2003. Reproductive biology and conservation status of the loggerhead sea turtles (Caretta caretta) in Espirito Santo State, Brazil. Chel. Conserv. Biol., 4(3): 523-529.

Binckley, C.A.; Spotila, J.R.; Wilson, K.S.; Paladino, F.V. 1998. Sex determination and sex ratios of Pacific leatherback turtles, Dermochelys coriacea. Copeia, 1998(2): 291-300.

Bjorndal, K.A.; Bolten, A.B. 1992. Spatial distribution of green turtle (Chelonia mydas) nests at Tortuguero, Costa Rica. Copeia, 1992(1): 45-53.

Bobyn, M.L.; Brooks, R.J. 1994. Incubation conditions as potential factors limiting the northern distribution of snapping turtles, Chelydra serpentina. Can. J. Zool., 72(1): 28-37.

Bodie, J.R. 2001. Stream and riparian management for freshwater turtles. J. Environm. Managem., 62: 443-455.

Bodie, J.R.; Semlitsch, R.D.; Renken, R.B. 2000. Diversity and structure of turtle assemblages: associations with wetland characters across a floodplain landscape. Ecography, 23(4): 444-456.

Bragg, W.K.; Fawcett, J.D.; Bragg, T.B. 2000. Nest-site selection in two eublepharid gecko species with temperature-dependent sex determination and one with genotypic sex determination. Biol. J. Linn. Soc., 69: 319-332.

Broderick, A.C.; Godley, B.J.; Reece, S.; Downie, J.R. 2000 Incubation periods and sex ratios of green turtles: highly female biased hatchling production in the eastern Mediterranean. Mar. Ecol. Prog. Ser., 202: 273-281.

Bull, J.J. 1980. Sex determination in reptiles. Q. Rev. Biol., 53(1): 3-20.

Bull, J.J.; Vogt, R.C. 1979. Temperature-dependent sex determination in turtles. Science, 206(7): 1186-1188.
Bull, J.J.; Vogt, R.C. 1981. Temperature-sensitive periods of sex determination in Emydid turtles. J. Exp. Zool., 218: 435-440.

Bull, J.J.; Charnov, E.L. 1989. Enigmatic reptilian sex ratios. Evolution, 43(7): 1561-1566.

Bull, J.J.; Vogt, R.C.; Bulmer, M.G. 1982a. Heritability of sex ratio in turtles with environmental sex determination. Evolution, 36(2): 333-341.

Bull, J.J.; Vogt, R.C.; McCoy, C.J. 1982b. Sex determining temperatures in turtles: a geographic comparison. Evolution, 36(2): 326-332.

Bull, J.J.; Legler, J.M.; Vogt, R.C. 1985. Non-temperature dependent sex determination in two suborders of turtles. Copeia, 1985(3): 784-786.

Bull, J.J.; Gutzke, W.H.N.; Bulmer, M.G. 1988. Nest choice in a captive lizard with temperature-dependent sex determination. J. Evol. Biol., 2: 177-184.

Burger, J. 1976a. Temperature relationships in nests of the northern diamondback terrapin, Malaclemys terrapin terrapin. Herpetologica, 32(4): 412-418.

Burger, J. 1976b. Behavior of hatchling diamondback terrapins (Malaclemys terrapin) in the field. Copeia, 1976(4): 742-749.

Burke, R.L.; Ewert, M.A.; McLemore, J.B.; Jackson, D.R. 1996. Temperature-dependent sex determination and hatchling success in the Gopher tortoise (Gopherus polyphemus). Chel. Conserv. Biol., 2(1): 86-88.

Bustard, H.R.; Greenham, P. 1968. Physical and chemical factors affecting hatchling in the green sea turtle, Chelonia mydas (L.). Ecology, 49(2): 269-276.

Carr, A. 1975. The Ascension Island Green Turtle Colony. Copeia, 1975(3): 425-429.

Carr, A.; Carr, M.H. 1972. Site fixity in the Caribbean green turtle. Ecology, 54: 547-555.

Charnier, M. 1966. Action de la temperature sur la sex-ratio chez l'embryon d'Agamma agama (Agamidae, Lacertilien). Soc. Biol. Ouest Afric., 160: 620-622.

Charnov, E.L.; Bull, J.J. 1977. When is sex environmentally determined? Nature, 266(5605): 828-830

Chevalier, J.; Godfrey, M.H.; Girondot, M. 1999. Significant difference of temperature-dependent sex determination between French Guiana (Atlantic) and Playa Grande (Costa Rica, Pacific) leatherbacks (Dermochelys coriacea). Ann. Sci. Nat. Zool., 20: 147-152.

Christens, E.; Bider, J.R. 1987. Nesting activity and hatching success of the painted turtle (Chrysemys picta marginata) in Southwestern Quebec. Herpetologica, 43(1): 55-65.

Congdon, J.D.; Nagle, R.D.; Kinney, O.M.; Osentoski, M.; Avery, H.W.; van Loben, C.R.S.; Tinckle, D.W. 2000. Nesting ecology and embryo mortality: implications for hatchling success and demography of Blanding's turtles (Emydoidea Blandingii). Chel. Conserv. Biol., 3(4): 569-579.

Conover, D.O.; van Voorhees, D.A.; Ehtisham, A. 1992. Sex ratio selection and evolution of environmental sex determination in 
laboratory populations of Menidia menidia. Evolution, 46(6): $1722-1730$

Donner Wright, D.M.; Bozek, M.A.; Probst, J.R.; Anderson, E.M. 1999. Response of turtle assemblage to environmental gradients in the St. Croix River in Minnesota and Wisconsin, U.S.A. Can. J. Zool., 77(6): 989-1000.

Eckert, K.L. 1987. Environmental unpredictability and leatherback sea turtle (Dermochelys coriacea) nest lost. Herpetologica, 43(3): 315-323.

Eendebak, B.T. 1995. Incubation period and sex ratio of Hermann's tortoise Testudo hermanni boettgeri. Chel. Conserv. Biol., 1(3): 227-231.

Ernst, C.H. 1970. Reproduction in Clemmys guttata. Herpetologica, 26(2): 228-232.

Ernst, C.H.; Barbour, R. W. 1989. Turtles of the World. Smithsonian Institution Press, Washington, USA. 313p.

Escalona, T.; Fa, J.E. 1998. Survival of nests of terecay turtle (Podocnemis unifilis) in the Nichare-Tawadu Rivers, Venezuela. J. Zool. (London), 244: 303-312.

Etchberger, C.R.; Ehrhart, L.M. 1987. The reproductive biology of the female loggerhead musk turtle, Sternotherus minor minor, from the southern part of its range in Central Florida. Herpetologica, 43(1): 66-73.

Ewert, M.A.; Nelson, C.E. 1991. Sex determination in turtles: diverse patterns and some possible adaptive values. Copeia, 1991(1): 50-68.

Ewert, M.A.; Jackson, D.R.; Nelson, C.E. 1994. Patterns of temperature-dependent sex determination in turtles. J. Exp. Zool., 270(1): 3-15.

Ewert, M.A.; Etcheberger, C.R.; Nelson, C.E. 2004. Turtle sexdetermination modes and TSD patterns, and some TSD patterns correlates. In: Valenzuela, N.; Lance, V.A. Temperature-Dependent Sex Determination in Vertebrates (Eds). Smithsonian Books, Washington. p. 21-32.

Ferguson, M.W.J.; Joanen, T. 1989. Temperature of egg incubation determines sex in Alligator mississippiensis. Nature, 296: 850853.

Ferreira Júnior, P.D. 2003. Influência dos processos sedimentológicos e geomorfológicos na escolha das áreas de nidificaçāo de Podocnemis expansa (tartaruga-da-amazônia) e Podocnemis unifilis (tracajá) na bacia do rio Araguaia. Tese de Doutorado, Departamento de Geologia, Universidade Federal de Ouro Preto, Ouro Preto, Minas Gerais, 296pp.

Ferreira Júnior, P.D.; Castro, P.T.A. 2003. Geological control of Podocnemis expansa and Podocnemis unifilis nesting areas in Rio Javaés, Bananal Island, Brazil. Acta Amazonica, 33(3): 445-468.

Ferreira Júnior, P.D.; Castro, P.T.A. 2005. Nest placement of the giant Amazon river turtle, Podocnemis expansa, in the Araguaia River, Goiás State, Brazil. Ambio, 34(3): 212-217.

Ferreira Júnior, P.D.; Guimarães, O.S.; Malvasio, A. 2003a. The influence of geological factors on reproductive aspects of Podocnemis unifilis (Testudines, Pelomedusidae), on the Javaés river, Araguaia National Park, Brazil. Chel. Conserv. Biol., 4(3): 626-634.

Ferreira Júnior, P.D.; Castro, P.T.A.; Addad, L.E.; De Lorenzo, M. 2003b Aspectos fisiográficos das áreas de nidificação da tartaruga marinha Caretta caretta na praia da Guanabara, Anchieta, Espírito Santo. Anais do Instituto Pau Brasil de História Natural, 7(1): $25-40$

Foley, M.A.; Peck, A.S.; Harman, R.G.; Richardson, L.W. 2000. Loggerhead turtle (Caretta caretta) nesting habitat on low-relief mangrove island in southwest Florida and consequences to hatchling sex ratios. Herpetologica, 56(4): 433-445.

Fowler, L.E. 1979. Hatching success and nest predation in the green sea turtle, Chelonia mydas, at Tortuguero, Costa Rica. Ecology, 60(5): 946-955.

Franco, M.T.O.M. 1994. Influência da temperatura de incubação na determinação sexual de Geochelone carbonaria (Spix, 1824) (Reptilia, Testudines, Testudinidae). Dissertação de Mestrado, Pontifícia Universidade Católica do Rio Grande do Sul, Porto Alegre.

Garmestani, A.S.; Percival, H.F.; Portier, K.M.; Rice, K.G. 2000. Nest-site selection by loggerhead sea turtle in Florida's Ten Thousand Island. J. Herpetol., 34(4): 504-510.

Georges, A. 1988. Sex determination is independent of incubation temperature in another chelid turtle, Chelonida longicollis. Copeia, 1988(1): 248-254.

Georges, A. 1989. Female turtle from hot nests: Is it duration of incubation or proportion of development that matters? Oecologia, 81: 323-328.

Georges, A. 1992. Thermal characteristics and sex determination in field nests of the pig-nosed turtle, Carattochelys insculpta (Chelonia: Carettochelydidae), from Australia. Aust. J. Zool., 40: 511-521.

Georges, A.; McInnis, S. 1998. Temperature fails to influence hatchling sex in another genus and species of chelid turtle, Elusor macrurus. J. Herpetol., 32: 596-598.

Georges, A.; Limpus, C.; Stoutjesdijk, R. 1994. Hatchling sex in the marine turtle Caretta caretta is determined by proportion of development at a temperature, not daily duration of exposure. J. Exp. Zool., 270(3): 432-444.

Georges, A.; Doody, S.; Beggs, K.; Young, J. 2004. Thermal models of TSD under laboratory and field conditions. In: Valenzuela, N.; Lance, V.A. Temperature-Dependent Sex Determination in Vertebrates (Eds). Smithsonian Books, Washington. p. 79-89.

Godfrey, M.H.; Barreto, R.; Mrosovsky, N. 1996. Estimating past and present sex ratio of sea turtles in Suriname. Can. J. Zool., 74(2): 267-277.

Godfrey, M.H.; D’Amato, A.F.; Marcovaldi, M.Â.; Mrosovsky, N. 1999. Pivotal temperature and predicted sex ratios for hatchling hawksbill turtles from Brazil. Can. J. Zool., 74(9): 1465-1473.

Godley, B.J.; Broderick, A.C.; Mrosovsky, N. 2001. Estimating hatchling sex ratios of loggerhead turtles in Cyprus from incubation durations. Mar. Ecol. Prog. Ser., 210: 195-201. 
Godley, B.J.; Broderick, A.C.; Hays, G.C. 2002. Temperaturedependent sex determination of Ascension Island green turtles. Mar. Ecol. Prog. Ser., 226: 115-124.

Gutzke, W.H.N.; Paukstis, G.L. 1983. Influence of the hydric environment of sexual differentiation of turtles. J. Exp. Zool., 226: 467-469.

Gutzke, W.H.N.; Paukstis, G.L. 1984. Sensitive periods for the influence of the hydric environment on eggs and hatchlings of painted turtles (Chrysemys picta). Physiol. Zool., 60(1):9-17.

Hays, G.C.; Speakman, J.R. 1993. Nest placement by loggerhead turtles, Caretta caretta. Anim. Behav., 45(1): 47-53.

Hays, G.C.; Godley, B.J.; Broderick, A.C.; 1999. Long-term thermal conditions on the nesting beaches of green turtles on Ascension Island. Mar. Ecol. Prog. Ser., 185(1): 297-299.

Hays, G.C.; Ashworth, J.S.; Barnsley, M.J.; Broderick, A.C.; Emery, D.R.; Godley, B.J.; Henwood, A.; Jones, E.L. 2001. The importance of sand albedo for the thermal conditions on sea turtle nesting beaches. Oikos, 93(1): 87-94.

Head, G.; May, R.M.; Pendleton, L. 1987. Environmental determination of sex in the reptiles. Nature, 329(6136): 198199.

Hewavisenthi, S.; Parmenter, J.C 2000. Hydric environment and sex determination in the flatback turtle (Natator depressus Garman) (Chelonia: Cheloniidae). Aust. J. Zool., 48(6): 653-659.

Horrocks, J.A.; Scott, N.M. 1991. Nest site location and nest success in the hawksbill turtle Eretmochelys imbricata in Barbados, West Indies. Mar. Ecol. Prog. Ser., 69(1): 1-8.

Iverson, J. B. 1992. A Revised Checklist with Distribution Maps of the Turtles of the World. Edited by the author (privately printed), Indiana, USA, 363pp.

Iverson, J.B.; Balgooyen, C.P.; Byrd, K.K., Lyddan, K.K 1993. Latitudinal variations in egg and clutch size in turtles. Can. J. Zool., 71(12): 2448-2461.

Janzen, F.J. 1994. Vegetational cover predicts the sex ratio of hatchling turtles in natural nests. Ecology, 75(6): 1593-1599.

Janzen, F.J.; Morjan, C.L. 2001. Repeatability of microenvironmentspecific nesting behaviour in a turtle with environmental sex determination. Anim. Behav., 62(1): 73-82.

Janzen, F.J.; Paukstis, G.L. 1991a. A preliminary test of the adaptive significance of environmental sex determination in reptiles. Evolution, 45(2): 435-440.

Janzen, F.J.; Paukstis, G.L. 1991b. Environmental sex determination in reptiles: ecology, evolution, and experimental design. Q. Rev. Biol, 66(2): 149-179.

Janzen, F.J.; Krenz, J.G. 2004. Phylogenetics: which was first, TSD or GSD?. In: Valenzuela, N.; Lance, V.A. Temperature-Dependent Sex Determination in Vertebrates (Eds). Smithsonian Books, Washington. p. 121-130.

Ji, X.; Chen, F.; Du, W.G.; Chen, H.L. 2003. Incubation temperature affects hatchling growth but not sexual phenotype in the Chinese soft-shelled turtle, Pelodiscus sinensis (Trionychidae). J. Zool., 261:409-416.
Kaska, Y.; Downie, R.; Tippett; Furness, R.W. 1998. Natural temperature regimes for loggerhead and green turtle nests in the eastern Mediterranean. Can. J. Zool., 76(4): 723-729.

Kikukawa, A.; Kamezaki, N.; Ota, H. 1999. Current status of the sea turtles nesting on Okinawajima and adjacent islands of the central Ryukyus, Japan. Biol. Conserv., 87(1): 149-153.

Kraemer, J.E.; Bell, R. 1980. Rain-induced mortality of eggs and hatchlings of loggerhead sea turtles (Caretta caretta) on the Georgia Coast. Herpetologica, 36(1): 72-77.

Krause, L.; Gomes, N.; Leyser, K.L. 1982. Observaçôes sobre a nidificação e desenvolvimento de Chrysemys dorbigni (Dumeril \& Bibron, 1835) (Testudines, Emydinae) na Estação Ecológica do Taim, Rio Grande do Sul. Rev. Bras. Zool., 1(1): 79-90.

Lance, V.A.; Valenzuela, N.; von Hildebran, H. 1992. A hormonal method to determine the sex of hatchling giant river turtle, Podocnemis expansa. Application to endangered species research. Am. Zool., 32: 16A.

Lang, J.W.; Andrews, H.; Whitaker, R. 1989. Sex determination and sex ratio in Crocodylus palustris. Am. Zool., 29(3): 935-952.

LeBuff Jr, C.R.; Beatty, R.W. 1971. Some aspects of nesting of the loggerhead turtle, Caretta caretta caretta (Linneu), on the Gulf Coast of Florida. Herpetologica, 27(4): 153-156.

Legler, J.M. 1954. Nesting habits of the western painted turtle, Chrysemys picta bellii (Gray). Herpetologica, 10(2): 137-144.

Lewis-Winokur, V.; Winokur, R.M. 1995. Incubation temperature affects sexual differentiation, incubation time, and posthatching survival in desert tortoises (Gopherus agassizi). Can. J. Zool., 73: 2091-2097.

Litzgus, J.D.; Brooks, R.J. 2000. Habitat and temperature selection of Clemmys guttata in a northern population. J. Herpetol., 34(2): $178-185$.

Malvasio, A., Souza, A.M., Ferreira Júnior, P. D., Reis, E. S., Sampaio, F. A. A. 2002. Temperatura de incubação dos ovos e granulometria dos sedimentos das covas relacionadas à determinação sexual em Podocnemis expansa (Schweigger, 1812) e P. unifilis (Troschel, 1848) (Testudines, Pelomedusidae). Publicaçôes Avulsas do Instituto Pau Brasil de História Natural. São Paulo, 5(1): 11-25.

Marcovaldi, M.A.; Godfrey, M.H.; Mrosovsky, N. 1997. Estimating sex ratios of loggerhead turtles in Brazil from pivotal incubation durations. Can. J. Zool., 75: 755-770.

Maxwell, J.A.; Motara, M.A.; Frank, G.H. 1988. A microenvironmental study of the effect of temperature on the sex ratios of the loggerhead turtle, Caretta caretta, from Tongaland, Natal. S. Afr. J. Zool., 23(4): 342-350.

McCoy, C.J.; Vogt, R.C.; Censky, E.J. 1983. Temperature-controlled sex determination in the sea turtle Lepidochelys olivacea. J. Herpetol., 17: 404-406.

McKnight, C.M.; Gutzke, W.H.N. 1993. Effects of the embryonic environment and of hatchling housing conditions on growth of young snapping turtles (Chelydra serpentina). Copeia, 1993(2): 475-482.

Milton, S.L.; Schulman, A.A.; Lutz, P.L. 1997. The effect of beach nourishment with aragonite versus silicate sand on beach 
temperature and loggerhead sea turtle nesting success. J. Coastal Res., 13(3): 904-915.

Moll, D. 1994. The ecology of sea beach nesting in slider turtles (Trachemys scripta venusta) from Caribbean Costa Rica. Chel. Conserv. Biol., 1(2): 107-116.

Mortimer, J.A. 1990. The influence of beach sand characteristics on the nesting behavior and clutch survival of green turtle (Chelonia mydas). Copeia, 1990: 802-817.

Mortimer, J.A.; Carr, A. 1987. Reproduction and migrations of Ascension Island green turtle (Chelonia mydas). Copeia, 1987(1): 103-113.

Mrosovsky, N. 1983. Ecology and nest-site selection of leatherback turtles. Biol. Conserv., 26(1): 47-56.

Mrosovsky, N. 1988. Pivotal temperatures for loggerhead turtles (Caretta caretta) from northern and southern nesting beaches. Can. J. Zool., 66(3): 661-669.

Mrosovsky, N. 1994. Sex ratios of sea turtles. J. Exp. Zool., 270(1): 16-27.

Mrosovsky, N.; Yntema, C.L. 1980. Temperature dependence of sexual differentiation in sea turtles: implications for conservation practices. Biol. Conserv., 18: 271-280.

Mrosovsky, N.; Provancha, J. 1989. Sex ratio of loggerhead sea turtles hatching on a Florida beach. Can. J. Zool., 67: 2533-2539.

Mrosovsky, N.; Dutton, P.H.; Whitmore, C.P. 1984. Sex ratio of two species of sea turtle nesting in Suriname. Can. J. Zool., 62(11): 2227-2239.

Mrosovsky, N.; Bass, A.; Corliss, L.A.; Richardson, J.I.; Richardson, T.H. 1992. Pivotal and beach temperatures for hawksbill turtles nesting in Antigua. Can. J. Zool., 70(10): 1920-1925.

Muth, A. 1980. Physiological ecology of desert iguana (Dipsosaurus dorsalis) eggs: temperature and water relations. Ecology, 61(6): 1335-1343.

Naro-Maciel, E.; Mrosovsky, N.; Marcovaldi, M.A. 1999. Thermal profiles of sea turtle hatcheries and nesting areas at Praia do Forte, Brazil. Chel. Conserv. Biol., 3(3): 407-413.

Packard, G.C. 1999. Water relations of chelonian eggs and embryos: is wetter better? Am. Zool., 39: 289-303.

Packard, G.C.; Packard, M.J. 1988. Water relations of embryonic snapping turtles (Chelydra serpentina) exposed to wet or dry environments at different times in incubation. Physiol. Zool., 61(1): 95-106.

Packard, G.C.; Packard, M.J.; Gutzke, W.H. 1985. Influence of hydration of the environment on eggs and embryos of the terrestrial turtle Terrapene ornata. Physiol. Zool., 58(5): 564575.

Petokas, P.J.; Alexander, M.M. 1980. The nesting of Chelydra serpentina in northern New York. J. Herpetol., 14: 239-244.

Pezzuti, J.C.B.; Vogt, R. 1999. Nesting ecology of Podocnemis sextuberculata (Testudines, Pelomedusidae) in the Japurá River, Amazonas, Brazil. Chel. Conserv. Biol., 3(3): 419-424.

Pieau, C. 1971. Sur la proportion sexuelle chez les embryons de deux chéloniens (Testudo graeca L. et Emys orbicularis L.) issus d'oefs incubés artificiellement. C. R. Hebd. Séanc. Acd. Sci Paris, 272D: 3071-3074.

Pieau, C. 1982. Modalities of the action of temperature on sexual differentiation in field developing embryos of the European pond turtle Emys orbicularis (Emydidae). J. Exp. Zool., 220: 353-360.

Pieau, C. 1996. Temperature variation and sex determination in reptiles. BioEssays, 18(1): 19-26.

Pieau, C.; Dorizzi, M. 1981. Determination of temperature sensitive stage for sexual differentiation of the gonads in embryos of the turtle, Emys orbicularis. J. Morphol., 170(3): 373-382.

Plummer, M.V. 1976. Some aspects of nesting success in the turtle, Trionyx muticus. Herpetologica, 32(4): 353-359.

Plummer, M.V.; Shadrix, C.E.; Cox, R.C. 1994. Thermal limits of incubation in embryos of softshell turtles (Apalone mutica). Chel. Conserv. Biol., 1: 141-144.

Pritchard, P.C.H.; Trebbau, P. 1984. The Turtles of Venezuela. Society for the Study of Amphibians and Reptiles, Caracas, Venezuela. $403 \mathrm{p}$

Reece, S.E.; Broderick, A.C.; Godley B.J.; West, S.A. 2002a. The effectas of incubation environmental phenotype in a natural pópulation of loggerhead turtles. Evol. Ecol. Res., 4: 737-748.

Reece, S.E.; Broderick, A.C.; Godley B.J.; West, S.A. 2002b. Extreme sex ratio of green (Chelonia mydas) and loggerhead (Caretta caretta) sea turtle nest in the Mediterranean and indirect methods for estimating sex ratio. http://westgroup.icapb.ed.ac.uk/SarahR/ pdfs/ Reece_et_al_02.pdf.

Rimblot, F.; Fretey, J.; Mrosovsky, N.; Lescure, J.; Pieau, C. 1985. Sexual differentiation as a function of the incubation temperature of eggs in the sea-turtle Dermochelys coriacea (Vandelli, 1976). Amphibia-Reptilia, 6(1): 83-92.

SBH. 2007. Brazilian reptiles - List of species. (www.sbherpetologia. org.br). Sociedade Brasileira de Herpetologia. Acesso: 08/01/2008.

Schwarzkopf, L.; Brooks, R.J. 1985. Sex determination in northern painted turtles: effect of incubation at constant and fluctuating temperatures. Can. J. Zool., 63(11): 2543-2547.

Schwarzkopf, L.; Brooks, R.J. 1987. Nest-site selection and offspring sex ratio in painted turtles, Chrysemys picta. Copeia, 1987(1): 53-61.

Servan, J.; Zaborski, P.; Dorrizi, M.; Pieau, C. 1989. Female-biased sex ratio in adults of the Emys orbicularis at the northern limit of its distribution in France: a probable consequence of interaction of temperature with genotype sex determination. Can. J. Zool., 67(5): 1279-1284.

Souza, R.R.; Vogt, R.C. 1994. Incubation temperature influences sex and hatchling size in the neotropical turtle Podocnemis unifilis. J. Herpetol., 28(4): 453-464.

Spotila, J.R.; Standora, E.A.; Morreale, S.J.; Ruiz, G. 1987. Temperature dependent sex determination in the green turtle (Chelonia mydas): effects on the sex ratio on a natural nesting beach. Herpetologica, 43(1): 74-81. 
Stancyk, S.E.; Ross, J.P. 1978. An analysis of sand from green turtle nesting beaches on Ascension Island. Copeia, 1978(1): 93-99.

Standing, K.L.; Herman, T.B.; Morrison, I.P. 1999. Nesting ecology of Blanding's turtle (Emydoidea blandingii) in Nova Scotia, the northeastern limit of the species' range. Can. J. Zool., 77(10): 1609-1614.

Standing, K.L.; Herman, T.B.; Morrison, I.P. 2000a. Developmental abnormalities in a northeastern population of Blanding's turtle, Emydoidea blandingii. Chel. Conserv. Biol., 3(4): 661-664.

Standing, K.L.; Herman, T.B.; Shallow, M.; Power, T.; Morrison, I.P. 2000b. Results of the nest protection program for Blanding's turtle in Kejimkujik National Park, Canada: 1987-1997. Chel. Conserv. Biol., 3(4): 637-642.

Standora, E.A.; Spotila, J.R. 1985. Temperature dependent sex determination in sea turtle. Copeia, 1985(3): 711-722.

Stoneburner, D.L.; Richardson, J.I. 1981. Observations on the role of temperature in loggerhead turtle nest selection. Copeia, 1981(1): 238-241.

Thompson, M.B. 1988a. Influence of incubation temperature and water potential on sex determination in Emydura macquarii (Testudines: Pleurodira). Herpetologica, 44(1): 86-90.

Thompson, M.B. 1988b. Nest temperatures in the Pleurodian Turtle, Emydura macquarii. Copeia, 1988(4): 996-1000.

Tinkle, D.W.; Congdon, J.D.; Rosen, P.C. 1981. Nesting frequency and success: implications for the demography of painted turtles. Ecology, 62(6): 1426-1432.

Valenzuela, N.; Lance, V.A. 2004. Temperature-Dependent Sex Determination in Vertebrates (Eds). Smithsonian Books, Washington, 194p.

Valenzuela, N.; Shikano, T. 2007. Dev. Genes Evol., 217(1): 55-62.

Valenzuela, N.; Botero, R.; Martínez, E. 1997. Field study of sex determination in Podocnemis expansa from Colombian Amazonia. Herpetologica, 53(3): 390-395.

Valenzuela, N.; Dean, C.A.; Bowden, R.M.; Gauger, A.C. 2004. Geometric morphometric sex estimation for hatchling turtles: a powerful alternative for detecting subtle sexual shape dimorphism. Copeia, 2004(4): 735-742.

Vogt, R.C. 1992. Ecologia reprodutiva de uma comunidade de quelônios da Amazônia. In: Congresso Latino-Americano de Zoologia, 12, Belém. Resumos, p.131.

Vogt, R.C.; Bull, J. 1982. Temperature controlled sex-determination in turtles: ecological and behavioral aspects. Herpetologica, 38(1): 156-164.

Vogt, R.C.; Bull, J. 1984. Ecology of hatchling sex ratio in map turtle. Ecology, 65(2): 582-587.

Vogt, R.C.; Flores-Villela, O.A. 1992. Effects of incubation temperature on sex determination in a community of neotropical freshwater turtle in southern Mexico. Herpetologica, 48(3): 265-270.
Vogt, R.C.; Bull, J.; McCoy, C.J.; Houseal, T.W. 1982. Incubation temperature influences sex determination in kinosternid turtles. Copeia, 1982(2): 480-482.

Vogt, R.C.; Cantarelli, V.H.; Carvalho, A.G. 1994. Reproduction of the cabeçudo, Peltocephalus dumerilianus, in the Biological Reserve of Rio Trombetas, Pará, Brazil. Chel. Conserv. Biol., 1(2): $145-148$.

Wang, H.C.; Cheng, I.J. 1999. Breeding biology of the green turtle Chelonia mydas (Reptilia: Cheloniidae), on Wan-An Island, PengHu archipelago. II. Nest site selection. Mar. Biol., 133(4): 603-609.

Weisrock, D.W.; Janzen, F.J. 2000. Thermal and fitness-related consequences of nest location in Painted Turtles (Chrysemys picta). Funct. Ecol., 13(1): 94-101.

Whitmore, C.P.; Dutton, P.H. 1985. Infertility, embryonic mortality and nest-site selection in leatherback and green sea turtles in Suriname. Biol. Conserv., 34(3): 251-272.

Wibbels, T.; Bull, J.J.; Crews, D. 1994. Temperature-dependent sex determination: a mechanistic approach. J. Exp. Zool., 270(1): 71-78.

Wibbels, T.; Rostal, D.; Byles, R. 1998. High pivotal temperature in the sex determination of olive riddley sea turtle, Lepidochelys olivacea, from Playa Nancite, Costa Rica. Copeia, 1998(4): 1086-1088.

Wilhoft, D.C.; Hotaling, E.; Franks, P. 1983. Effects of temperature on sex determination in embryos of the snapping turtles, Chelydra serpentina. J. Herpetol., 17(1): 38-42.

Wilson, D.S. 1998. Nest-site selection: microhabitat variation and its effects on the survival of turtle embryos. J. Herpetol., 22(1): 88-96.

Yntema, C.L. 1968. A series of stages in the embryonic development of Chelydra serpentina. J. Morphol., 125: 219-251.

Yntema, C.L. 1976. Effects of incubation temperatures on sexual differentiation in the turtle, Chelydra serpentina. J. Morphol., 150(2): 453-462.

Yntema, C.L. 1978. Incubation times for eggs of the turtle Chelydra serpentina (Testudines: Chelydridae) at various temperatures. Herpetologica, 34(3): 274-277.

Yntema, C.L. 1979. Temperature levels and periods of sex determination during incubation of eggs of Chelydra serpentina. J. Morphol., 159(1): 17-28.

Yntema, C.L.; Mrosovsky, N. 1982. Critical periods and pivotal temperatures for sexual differentiation in loggerhead sea turtles. Can. J. Zool., 60(5): 1012-1016.

Recebido em 06/02/2006

Aceito em 03/02/2009 